\title{
The Role of Background Knowledge in Foreign Language Listening Comprehension
}

\author{
Samad Salahshuri \\ Department of English, Najafabad Branch, Islamic Azad University, Najafabad, Iran \\ Email: tabatabaeiomid@yahoo.com
}

\begin{abstract}
The role of background knowledge and topic familiarity in second language reading comprehension has been the subject of much research. Although it is assumed that learners will react similarly to listening, it should be remembered that, they are not entirely parallel skills, and most importantly, relevant researches provided conflicting results in different contexts. Besides, there is no report of such a study with Iranian learners of a foreign language. Thus, this paper reports research that describes the effects of topic familiarity on the foreign language listening comprehension, and makes an attempt to find out whether proficiency level affects recall measures of listening comprehension. To this end, an experiment was conducted with 56 students studying English at one of Iranian universities. The results of the between-within analysis of variance clearly indicated that topic familiarity affected the scores of recall measures and the course-level groups revealed a consistent increase in comprehension scores. There was also no interaction effect: subjects regardless of their level scored higher on the familiar passage. The researcher has also left some relevant issues to some further research at the end of the paper.
\end{abstract}

Index Terms - recall measures, topic familiarity, schema theory, protocol analysis

\section{BACKGROUND AND PURPOSE}

In recent years, the fields of cognitive psychology, artificial intelligence and linguistics have combined efforts in developing theories of comprehension based on learner's ability to draw on their existing world knowledge (Long \& Reseigh, 1989). Along the same lines, new models of listening consider listening as an active productive process in which background knowledge plays a significant role. Murphy and Cooper (1995) state that prior to the 1970s, listening was characterized as a receptive skill, and it was believed that listeners would passively assimilate the information presented to them, but during the 1970s cognitive psychology began to focus on the individual as an active processor of linguistic input (Long \& Reseigh, 1989). So, the current models such as interactional, cybernetic, and transactional frames of reference have highlighted the background knowledge as a critical component of listening process (Murphy \& Cooper, 1995). For instance, Lynch (1996) emphasizes that in many cases it is our unfamiliarity with the appropriate background knowledge that prevents us understanding something, rather than inadequate knowledge of the language. He and Anderson (1998, cited in Schmit-Rinehart 1994) refer to schematic knowledge as one of the information sources in comprehension. Also, Rost (1990, cited in Schmidt-Rinehart 1994) introduces editing principles and procedures, such as application of cultural schema and filling in schematic slots, for the construction of meaning.

Background knowledge has been defined in a variety of ways such as religious, technical and cultural knowledge or topic familiarity. Concerning the relationship between listening comprehension and prior knowledge, some studies have been carried out by Bransford, Johnson, Anderson and Steffensen et al. (Schmidt-Rinchart, 1994). Their findings supported the idea that prior knowledge would aid comprehension of the first language. This triggered the investigation of the same phenomenon for the second language.

Kintsch Walter and Van Dijk (1978, cited in Lynch, 1996) worked toward a model of text comprehension and production. They described the system of mental operations that would underline the processes occurring in text comprehension, in the production of recall, and summarization protocol. They concluded that familiarity might have effects on comprehension not only at the level of processing of the construction of a coherent text but also at other higher processing levels.

In order to determine the influence of religious background knowledge on the listening comprehension of EFL learners of different religions, Markham and Latham (1988) used passages describing prayer rituals of Islam and Christianity. The subjects recalled more information and provided more elaborations, but fewer distortions for the passage that was related to their own religion.

Muller (1980) investigated the effects of a contextual visual on recall measures of listening comprehension and the effects of varying the locus of the contextual visual in the sequence of events, before and after the passage, on recall measures of listening comprehension. He also examined the effects of a contextual visual with the students' aptitude as measured by prior achievement in language learning. He found out that the learners who had contextual visual before hearing the passage scored significantly higher on the recall measure than those in the Visual-After and No-Visual groups. 
Bacon (1992) experimented the three phases of listening comprehension which were proposed by Anderson: perceptual, parsing and utilization (connecting what is heard with what is already known). The results showed that the subjects made little use of advanced organizers during the perceptual phase but effective use of previous knowledge during the third phase. Accordingly, the successful listeners used their world, personal, and discourse knowledge appropriately.

Chiang and Dunkel (1992) had an experiment with Chinese EFL students. The subjects listened to two lectures and their comprehension was measured by a multiple-choice test that had both passage dependent and passage independent items. The subjects scored higher on the familiar topic lecture than on the unfamiliar topic lecture. The results showed a significant effect on the passage-independent items. They concluded that the interaction between prior knowledge and test type might show that passage-independent items had provided a measure of background knowledge, but its effect on comprehension of information from the passage remained unclear.

Jensen and Christa Hansan (1995) investigated the effects of prior knowledge on English for Academic Purposes (EAP) in a listening-test performance. They reported findings which were not in accordance with the preceding findings. Their findings did not support the hypothesis that high-proficiency listeners who had indicated prior study of a topic would perform better on lecture comprehension. Although prior knowledge was a significant main effect for five of the eleven lectures, the effect size was trivial.

It has been assumed that comprehension is a general construct that applies to both modalities (listening and reading) and even the principles of reading comprehension can be imported to listening as well (Lund, 1991, cited in Lynch, 1996). Concerning the role of background knowledge and comprehension, more studies have also been carried out on reading comprehension. In a study, subjects from The United States and India read letters about an Indian and American wedding and recalled them following interpolated tasks. Subjects recalled a larger amount of information from the native passage and produced more culturally based distortions of the foreign passage. Whether recalling the native or foreign passage, subjects recalled more of the text elements considered as important by other subjects with the same cultural heritage. The results were interpreted as showing the pervasive influence on comprehension and memory of schemata embodying knowledge of the context of a discourse (Steffensen, Joag-Dev, \& Anderson, 1979).

In another study done by Carrell (1983), three components of background knowledge in reading comprehensioncontents, text transparency and familiarity-were investigated. She investigated native and non-native readers and reached almost different results. She reported that EFL readers did not process text as native speakers did. Neither advanced nor high intermediate EFL readers appeared to utilize context or textual clues, but only advanced EFL readers were affected by familiarity -the more novel and salient the text, the better recalled in short-term memory.

Carrell (1987) investigated the simultaneous effects on ESL reading comprehension of both culture-specific content schemata and formal schemata as well as any potential interaction between them. For each of two groups of readers (students of Muslim and Catholic/Spanish backgrounds), one text had culturally familiar content. Within each groups, one half of the subjects read the text in a familiar rhetorical format and the other half read the text in an unfamiliar rhetorical format. Results showed familiar content and familiar rhetorical form yielded good reading comprehension. In contrast, unfamiliar content and unfamiliar rhetorical form yielded poor reading comprehension.

In sum, the majority of studies on the effects of background knowledge have investigated second language reading. Although it is assumed that learners will react similarly to listening, it should be remembered that they are not entirely parallel skills. There is a difference between oral and written discourse, so the field of EFL research is in need of studies that investigate listening as a unique skill. Another point is that their results are not the same; sometimes they reached conflicting results in different contexts. Besides, there is no report of such a study with Iranian learners of a foreign language.

The present study whose main purpose is to investigate effects of topic familiarity on the second language comprehension is the replication of the research done by Barbara Schmidt-Rinehart with the University Students of Spanish in Mid-Western in the United States.

\section{RESEARCH QUESTIONS}

This study is designed to investigate the following questions:

- Does topic familiarity affect recall measures of listening comprehension of foreign language learners?

- Does proficiency level affect recall measures of listening comprehension?

It was assumed that foreign language learners, studying English at Najafabad Azad University, Iran, would comprehend better when the topic was familiar to them in comparison with the case that it was unfamiliar. Besides, one would expect that increased level of oral language proficiency (indicated by course level) would affect listening comprehension. In this study, the researcher has made no distinction between the second and foreign language and has used the term "second" for both.

\section{MethodOLOGY}

A. Subjects 
The subjects were the first-semester and third-semester students of English (Teaching) at Najafabad Azad University. Respectively, they were enrolled in Lab classes of one and two. The study was conducted with subjects $(\mathrm{N}=56)$. The number of the first semester subjects was twenty-three and the number of the third-semester subjects was thirty-three. This experiment was carried out with these subjects under natural school conditions because it was the situation which has already existed in the real world and was more representative of the conditions found in educational contexts.

\section{B. Variables}

Course Level: The first independent variable of this study consisted of two levels of English proficiency determined by their course level: level I (those who took part in Lab I) and level II (those who took part in Lab II).

Topic Familiarity: The background knowledge was defined in terms of topic familiarity as our second independent variable, which consisted of two levels as determined by previous exposure to the information contained in the passage and a questionnaire following the listening tasks; therefore, either the topic was familiar or unfamiliar.

Immediate Protocol Recall Test: The dependent variable was proficiency which was operationalized in terms of listening scores of language protocol test.

\section{Instruments and Procedures.}

Two passages were used for the experiment (Appendix I). Passage one was about a familiar topic "Madrid", and passage two was about an unfamiliar topic "The Lemming." The passage about familiar topic (Madrid) was from Interchange cassettes, and the second passage (The Lemming) was taken from American streamline. These two passages were transcribed into written form in order to determine the values for scoring based on "idea units". The idea unit analysis was based on semantic importance of propositions or phrases (Riley and Lee 1996). Therefore, the semantically-weighted scoring system was used. The total score for each passage was 40 . In order to attribute the familiarity variable to the topic familiarity, efforts were made to choose passages which were equitable as much as possible in terms of length, difficulty, and word rate. ${ }^{1}$ A comparison of the two passages according to six factors indicated that the passages were almost identical in each of the categories (Appendix II).

The text was conducted in the language laboratory during a regularly scheduled fifty-minute class session. The test for the first semester subjects was given in one session and the test for the third semester subjects was given in another session. The interval between the two sessions of tests was one day.

The test had three stages. First, concerning questions about the familiar topic, a questionnaire was distributed. Because it was very important that the subjects had already had background knowledge about the topic "Madrid", a pilot study had been carried out on this questionnaire to test the research instrument and their suitability.

Then at the second stage, the instructions were given to them. The subjects were informed that they were to listen to two passages separately, try to understand each of them, and then recall the passage in English. Because it was very important for subjects to clearly understand what level of details and original sentence structures they were to produce, their instructions were to write as much as they could remember. Each tape was played twice ${ }^{2}$. They did not write any information during the first playing of the recording. After the second playing, they wrote what they could remember. Enough time was given to them (15 minutes for each passage). After the completion of the second recall, their protocol papers were collected to prevent them from getting any information out of the post-listening questionnaire. Then at stage three, a post-questionnaire was distributed to check their unfamiliarity with "The Lemming" passage. ${ }^{3}$ Any subject who indicated that $\mathrm{s} /$ he had prior knowledge with "The Lemming" topic was excluded from the analysis.

\section{Data Analysis}

The pre-listening and post-listening questionnaires were examined. Only two subjects from level one were eliminated because the topic of "Madrid" was not familiar to them. Then, the immediate recall protocols written by subjects were analyzed into units and were scored according to the value given to idea units. The scores of fifty-four subjects were arranged for an analysis of variance. A $2 \times 2$ way analysis of variance (factorial design) was performed on the recall protocol scores of fifty-four subjects. The results of analysis of variance by course level and familiarity are summarized in Table I.

TABLE 1

ANALYSIS OF VARIANCE BY COURSE LEVEL \& FAMILIARITY

\begin{tabular}{|l|l|l|l|l|l|}
\hline Source & SS & DF & MS & F & Sig of F \\
\hline Between & & & & & \\
Familiarity (Factor A) & 319.10 & 1 & 319.10 & $* 16.85$ & .000 \\
Course Level (Factor B) & 144.96 & 1 & 144.96 & $* 7.65$ & .007 \\
Factor A by Factor B & 21.91 & 1 & 21.91 & 1.16 & .285 \\
Within + Residual & 1969.81 & 104 & 18.94 & & \\
\hline Total & 2488.77 & 109 & 23.26 & & \\
\hline$* \mathrm{P}<.05$ & \multicolumn{5}{|l|}{} \\
\hline
\end{tabular}

The main effect of the independent variable of familiarity was highly significant at .05 level $(\mathrm{P}<.05)$, even at .001 level. As can be seen by the group means in Table II, subjects scored highly on the familiar topic than on the novel topic. 
TABLE 2

GROUP MEANS \& STANDARD DEVIATIONS

\begin{tabular}{|l|l|l|l|l|}
\hline \multirow{2}{*}{ Course Level } & Familiar Topic & SD & Unfamiliar Topic \\
\cline { 2 - 5 } & Mean & 4 & Mean & SD \\
\hline Level 1 & 8.39 & 5.10 & 5.83 & 3.63 \\
\hline Level 3 & 11.64 & 7.26 & 4.27 \\
\hline
\end{tabular}

The analysis revealed no interaction between the levels of familiarity and course level. In other words, familiarity effects did not vary according to the course level. The third semester subjects did better than the first semester subjects regardless of the background knowledge topic (Figure I).

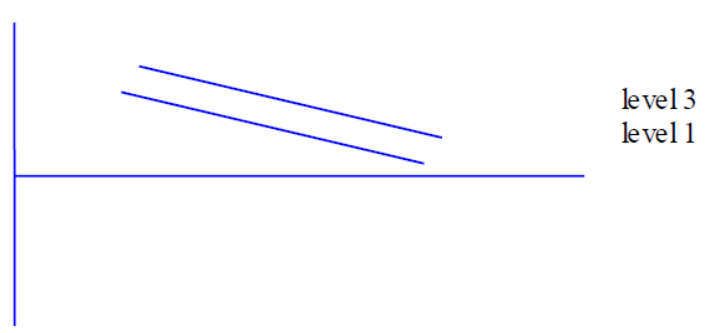

Figure I: Topic Familiarity Topic Unfamiliarity

The independent variable of course level (factor B) also reached statistical significance at $\mathrm{P}<.05$ level. Because there was no interaction effect, a t-test was done between two levels of learners to ensure that the aforementioned difference between the means of the protocol scores of course level would be significant. The obtained value was $t=.88$ which was significant at $.05(* \mathrm{P}<.05)$ level.

Later, in the examination of the post-listening questionnaire, $80 \%$ of subjects, as a whole, expressed that they understood "Madrid" better than "The Lemming". Among the first semester learners $74 \%$ claimed that "Madrid" was easier for them and only 13\% said that "The Lemming" was easier. Among the third semester subjects $84 \%$ expressed that they understood "Madrid" better, while 13\% claimed that "The Lemming" was easier for them.

In post-listening activity, the subjects also gave answers to their problems relating to comprehension and some of them wrote their comments ${ }^{4}$. Their answers were analyzed, and the results showed that almost $25 \%$ of subjects claimed that whenever a non-native speakers of English, whose first language was Persian were speaking, they could understand while they had difficulty in comprehension with native speakers of English. In other words, they indicated that they experienced difficulty making transition from understanding classroom talk to understanding natural language. Almost $26 \%$ of the subjects (of which more were the first semester learners) said that they could understand the meaning of single words, but they had problems with the whole concepts of the passage and they could not keep up with the speaker. Almost $41 \%$ of the subjects (of which more were the third semester learners) claimed that they could get the whole concept or general meaning, but they had problems with detailed information of the passage, and almost $6 \%$ of the subjects claimed that they understood neither the general concept nor the details.

\section{SUMMARY AND SUGGESTIONS}

In regard to the first research question of the present study, the results of the between-within analysis of variance clearly indicated that topic familiarity affected the scores of recall measure. Addressing the second question, the analysis of variance demonstrated that the course-level groups revealed a consistent increase in comprehension scores. Finally, there was no interaction effect: subjects regardless of their level scored higher on the familiar passage. There are some points to be taken into considerations. First, only one measure of comprehension was used in this study. In order words, the learners were asked to recall as much as possible. Shohamy (1984, cited in Riley and Lee, 1996) states that the methods of assessing comprehension influence and perhaps determine how readers perform on a test of comprehension. Therefore, there is a difference between summary and recall protocol. In this study a strict criterion was adapted in which distortions of the original text were not allowed. Moreover, elaborate inferences and paraphrases were not allowed. Riley and Lee (1996) reported significant differences in performance on two tasks. The summaries contain significantly more main ideas than recall protocols. Therefore, the low presentation of important idea units may be due to the listener's perception of the recall task itself. This may account for the problem of $28 \%$ of learners that could not get the whole concept or main ideas. Care should be taken because learners' performance on recall protocol may not be a true indication of their ability to understand the passage. The second point is that short-term memory may have been a factor in their demonstration of comprehension. This may account for the problem of $41 \%$ of subjects that could not retain or remember details. Another point is that some learners have problems with comprehension of authentic language (26\% in this study). Their answers suggest that teachers should expose them more to the natural spoken language of everyday life as distinguishable from written language. The final point is that educators should advocate the use of advance organizers and other types of pre-listening exercises that can activate background knowledge. It is important for teachers to recognize that students' existing knowledge contributes significantly to the comprehension, 
and listening is no longer a passive activity. The result of this study might show that learners should build a mental framework with which to link the new information to what they already know.

\section{FURTHER RESEARCH}

The researcher feels a need for several directions for future research: Do all learners at different levels (elementary, pre-intermediate, intermediate and advanced) use the schema-based processing to the same degree? Do listening proficiency levels override the background knowledge at all levels? Besides, different response modes, especially the other authentic tasks, can be used to examine the effect of background knowledge on second language listening comprehension. The researcher leaves these issues to more future research in this area.

\section{Appendix I}

\section{Madrid}

Today I am going to talk about Madrid. Madrid is the capital of Spain and is located right in the center of the country. It is also the largest city in the Spain with over three million residents. Madrid is a center for government and finance and is an important manufacturing center with automotive and aircraft industries. In addition, it is one of the major publishing centers for Spanish-speaking world. The people of Madrid are called "madrilènes". Many madrilènes work from ten a.m. to two p.m. Then at two o'clock many stores and offices close. This custom started so that the people could take an afternoon nap or "siesta". Those who take a "siesta" go back again from five to eight o'clock. However, recently many businesses have stopped closing for the "siesta".

The Lemming

The Brown Lemming is a small mammal (4-7 inches long) found all over the Northern parts of North America and Europe. Lemmings usually make short, annual migrations in the spring, traveling by night and feeding and sleeping by

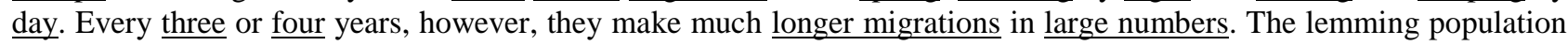
seems to change over a three or four year cycle, from one lemming per acre to between $\underline{400}$ and $\underline{700}$ lemmings per acre. Migration seems to be a method of population control and is most spectacular in the well-known "mass suicides," where thousands of lemmings plunge over cliff tops into the sea and swim until they die of exhaustion. These "mass suicide" only occur infrequently and then only in Norway where mountains touch the sea.

Appendix II.

\begin{tabular}{|c|c|}
\hline Madrid & The Lemming \\
\hline Length of the passage in seconds ........... 51 & 53 \\
\hline Length of the passage in characters ........ 653 & 650 \\
\hline Length of the passage in words ............. 135 & 133 \\
\hline Lines of the passage …........................ 12 & 12 \\
\hline *Readability of the passage .................... 34.50 & 39.46 \\
\hline 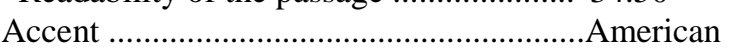 & American \\
\hline
\end{tabular}

*Schulz (1981, P. 53) introduces norms in the interpreting the Lix formula results and range 35-40 under one category (easy texts).

$$
\text { Lix }=\frac{\text { number of words }}{\text { number of sentences }}+\frac{\text { number of long words }}{\text { number of words }} \times 100
$$

Notes

1. Schulz (1981) believed that foreign language learners should not be exposed to authentic texts indiscriminately chosen without regard to linguistic difficulty and emotional maturity. Klare (1974-75) states three ways or solutions to recognize whether a particular test is likely readable to a particular group. One way is "guess" or instructor judgment. The second way is using a test (usually a cloze procedure developed by Taylor) and the third is readability formulas. In this study, although the instructor judgment is not ignored, the focus has been on the readability formula, which can be used for reading as well as listening skill, because the instructor judgment may vary from person to person and it may be subjective. Among readability formulas, the Lix formula (Schulz, 1981) has been used because this formula can be used for the second language as well as the first language and its results have shown the close relationship with other statistic formulas. The Lix device simply measures the sum of average sentence length and percentage of "long words" in terms of letters with the following formula:

$$
\text { Lix }=\frac{\text { numberof words }}{\text { numberof sentences }}+\frac{\text { number of long words }}{\text { number of words }} \times 100
$$

*A long word is the one that has more than three syllables. 
2. The post-listening questionnaire contained three questions to illicit information about their problems, to probe prior familiarity with the topics and the learner's judgment about two passages.

3. Bernhardt and James (cited in Schmidt-Rinehart, 1994) claim that the passage should be played two times: once to familiarize the subjects with the text and once to establish a mental structure with which to retain aspects of the text needed for generating a protocol.

4. Some students commented that they could not concentrate on their task, and their attentions would be distracted. These issues should be discussed in psychological and affective domains which are beyond the scope of this study. However, those comments show the complexity of the issue and caution us against the definite generalization of results.

\section{REFERENCES}

[1] Bacon, S. M. (1992). The relationship between gender, comprehension processing strategies, cognitive and affective response in foreign language listening. Modern language Journal, 76(2), 161-178.

[2] Carrell, P. L. (1989). Content and formal schemata in ESL reading. TESOL Quarterly, 21(3), 461-481.

[3] Carrell, P. L. (1983). Three components of background knowledge in reading comprehension, Language Learning. 34, 183203.

[4] Chiang, Chang Shing \& Dunkel Patricia. (1992). The effect of speech modification, prior knowledge and listening proficiency on EFL lecture learning. TESOL Quarterly, 26(2), 345-380.

[5] Jensen, Christine \& Hansen, Christa. (1995). The effect of prior knowledge on EAP listening test performance. Language Testing, 12(3), 99-120.

[6] Kintsch, Walter \& Van Dijk, Teun A. (1998). Toward a model of text comprehension and production. Psychological Review, 85(5), 363-395.

[7] Klare, J. (1975). Assessing readability. Reading Research Quarterly. 10, 62-98.

[8] Long, Donna Reseigh. (1989). Second language listening comprehension: A schema-theoretic perspective. Modern Language Journal, 73(1), 32-48.

[9] Land, Randall J. (1991). A comparison of second language listening and reading comprehension. Modern Language Journal, 75(2), 196-202.

[10] Lynch, Tony. (1996). Communication in the Language Classroom. New York: Oxford University Press, 24.

[11] Muller, Gunther A. (1980). Visual Contextual Cues and Listening Comprehension: An Experiment. Modern Language Journal, 64(3), 335-40.

[12] Murphy, D and J. Cooper (1995). Getting the Message. Cambridge, Cambridge University Press.

[13] Oxford, Rebecca L. (1993). Research update on teaching L2 listening. System. 2, 205-211.

[14] Riazi, Mehdi A. (1999). A dictionary of Research methods: Quantitative and qualitative. Tehran: Rahnama Publications.

[15] Riley, Guil L. \& Lee, James F. (1996). A comparison of recall and summary protocol as measures of second language reading comprehension. Language Learning, 13(2), 173-89.

[16] Schmidt-Rinehart, Barbara C. (1994). The effect of topic familiarity on second language listening comprehension. Modern Language Journal, 78(2), 190-89.

[17] Schulz, Renate A. (1981). Literature and readability: Bridging the gap in foreign language reading. Modern Language Journal. 65, 43-53.

[18] Steffensen, Margaret S. et al. (1949). A cross-cultural perspective on reading comprehension. Reading Research Quarterly. 1, 10-29.

Samad Salahshuri is a lecturer at Islamic Azad University, Najafabad Branch, Iran. He has been involved in teaching various TEFL courses at BA level. His areas of interest are: teaching skills, idioms learning, and materials development. 